MATEC Web of Conferences 9, 03004 (2013)

DOI: $10.1051 /$ matecconf/20130903004

(C) Owned by the authors, published by EDP Sciences, 2013

\title{
Contribution to the study by numerical simulation of a fire plume coming out through a window on façade "Application to the comprehension of the wind influence on an eventually stack effect"
}

\author{
Bernardo Martinez R. ${ }^{\mathrm{a}}$ \\ CSTB Centre Scientifique et Technique du Batiment France, \\ 84, avenue Jean Jaurès Champs sur Marne, 77447 Marne la Vallée Cedex 2, France
}

\section{INTRODUCTION}

The fire that occurred in a social housing in Dijon (France) in November 2010 has raised questions about a possible stack effect due to the frontage of façade and its influence on the vertical extension of the fire by the outside. In this study, we handle this problem using the numerical simulation of fluids mechanics CFD and the LES numerical approach of the turbulence. Admittedly, the simulation allows us to have access to variables and physical phenomena, but still now, the analytical models are limited to deal with certain multi physics problems. Strong assumptions need to be done in order to model a problem as the one considered here "façade supposed inert", although formed by various coated with a coating of insulation. Thus, this study does not take into account (and not solves) the coupled phenomena of the pyrolysis of the organic reinforced coating and expanded polystyrene (insulation from the outside) and the dynamics of a fire plume emerging through an open window and the influence of a fluctuating wind (the wind is considered to be a constant speed).

In order to simplify, we decided to build the studied configuration as two superposed rooms with a front façade having windows in the ground and first floor levels (the first floor window is supposed always closed, the broken of its glass is not studied either) with a back façade without windows (cf. Fig. 1). The outer walls are forming an inside corner of the $90^{\circ}$ ( $90^{\circ}$ dihedral configuration) and other second dihedral configuration forming an inside corner of the $135^{\circ}$. This study aims to:

Simulate a fire plume, which emerges from the window of the room on the ground floor. The fire plume has a nominal power of $2 \mathrm{MW}$;

Analyze the fire plume dynamics under the influence of two wind speeds: $60 \mathrm{~km} \mathrm{~h}^{-1}$ and $30 \mathrm{~km} \mathrm{~h}^{-1}$;

$>$ Analyze the influence of the angle of the dihedral configuration (by modeling two dihedral opening angles: $90^{\circ}$ and $135^{\circ}$ );

$>$ Analyze the influence of the position of the window from which the fire plume emerges (changing the window's position to the walls dihedral side), while keeping the same wind direction (parallel to the plane bisecting the dihedral configuration).

\footnotetext{
${ }^{a}$ e-mail: bernardo.martinez-ramirez@cstb.fr
}

This is an Open Access article distributed under the terms of the Creative Commons Attribution License 2.0, which permits unrestricted use, distribution, and reproduction in any medium, provided the original work is properly cited. 


\section{MATEC Web of Conferences}

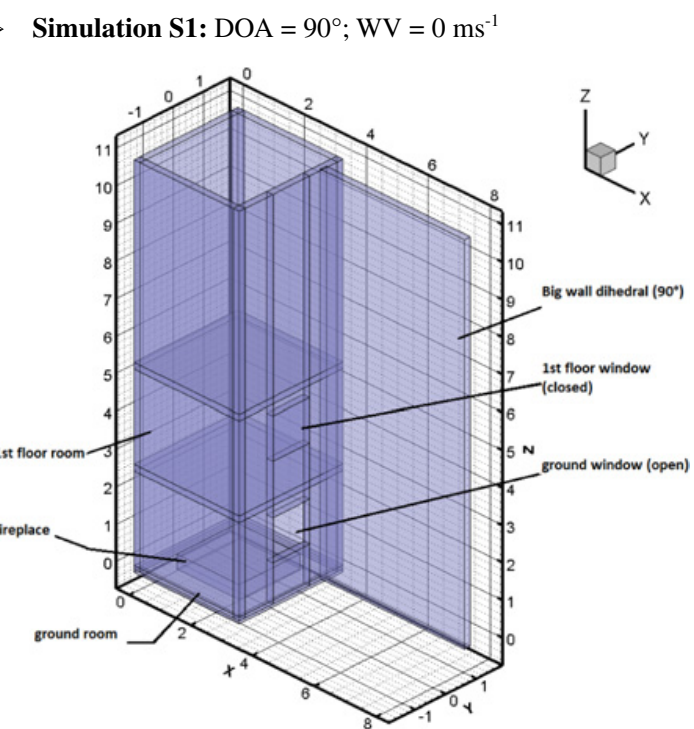

Figure 1. Numerical domain of S1 simulation.

\section{THE CFD CODE FDS, THE HARDWARE DEVICES}

The software used in this work was the code "Fire Dynamics Simulator V5" (FDS V5.5.3) developed by the National Institute of Standards and Technology (USA). FDS is a computational fluid dynamics (CFD) model of fire-driven fluid flow. FDS solves numerically a form of the Navier-Stokes equations for low-speed (low Mach number), non-compressible thermally-driven flow, with an emphasis on soot masse fraction (smoke) and heat transport from fires. The calculus was performed in a DELL work station ( 8 processors and 4 MB RAM memory), in parallel using the OpenMP (Open Multiprocessing) application programing interface (API) that supports multi-platform shared memory multiprocessing programming. Using OpenMP we save the time to cutting the numerical grid and the post treatment of data results.

\section{THE NUMERICAL MODEL}

The numerical model has the following characteristics:

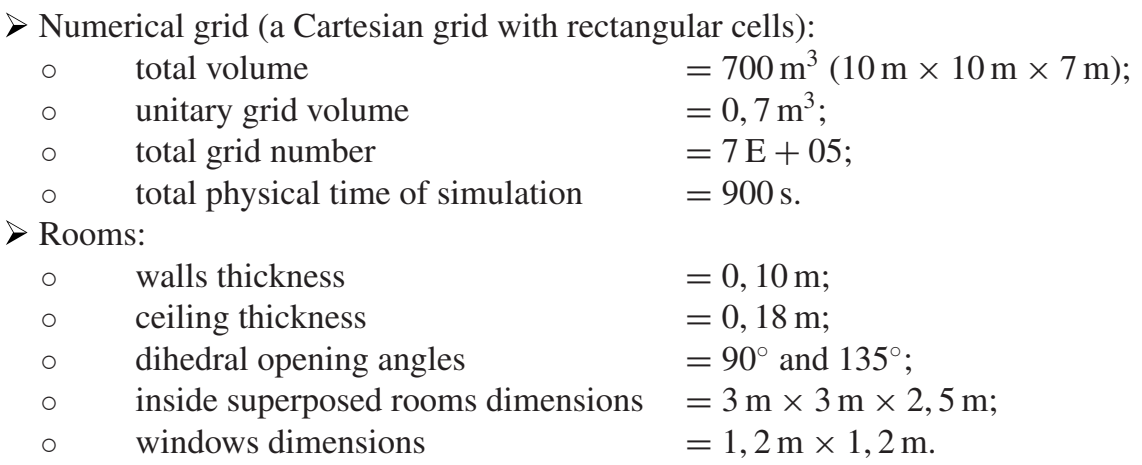


Fireplace:

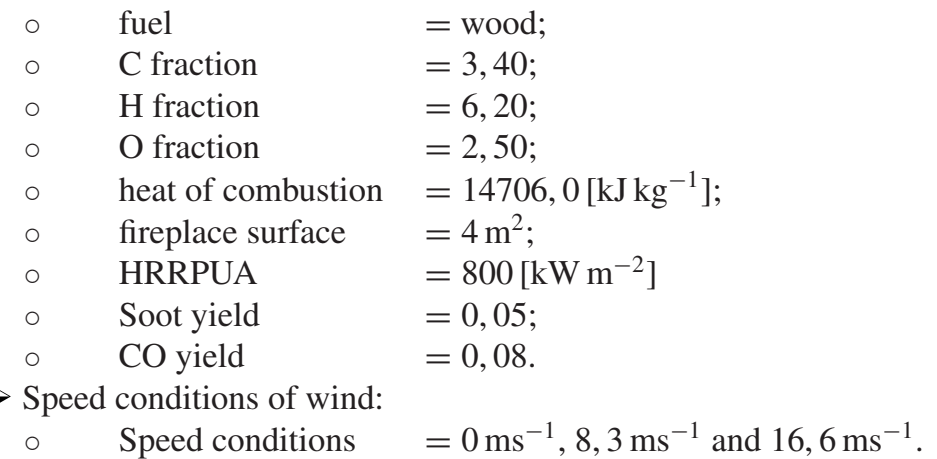

The resulting numerical model created with this data is shown on Figure 1 and Figure 7.

\section{THE SIMULATIONS CONDITIONS}

A total of 8 different conditions were simulated in this work. Table 1 shows the summary of simulations parameters. The $1^{\text {st }}$ simulation (S1) is used to estimate the height of the fire plume in a quiet atmosphere (without the wind influence).The $2^{\text {nd }}$ and $3^{\text {rd }}$ simulations (S2 and S3) are used to determinate the wind influence on the fire plume dynamics with the direction of wind perpendicular to the windows from which the fire plume emerges (condition of the frontal wind). The $4^{\text {th }}$ to $6^{\text {th }}$ simulations (S4, S5 and S6) are used to evaluate the wind speed influence and the dihedral opening angle on the fire plume dynamics and the last two simulations (S7 and S8) to evaluate the influence of the window position.

Table 1. Summary of simulations parameters.

\begin{tabular}{|c|c|c|c|c|}
\hline \multirow{3}{*}{ Simulation } & \multicolumn{4}{|c|}{ Parameters } \\
\hline & \multirow{2}{*}{$\begin{array}{c}\text { Dihedral } \\
\text { opening angle } \\
\text { (DOA) }\end{array}$} & \multirow{2}{*}{$\begin{array}{l}\text { Window } \\
\text { position }\end{array}$} & \multicolumn{2}{|l|}{ Wind conditions } \\
\hline & & & Direction & $\begin{array}{l}\text { velocity } \\
{\left[\mathrm{ms}^{-1}\right]}\end{array}$ \\
\hline S1 & $90^{\circ}$ & \multirow{7}{*}{$\begin{array}{l}\text { On the little } \\
\text { wall of dihedral } \\
\text { configuration }\end{array}$} & nothing & 0 \\
\hline $\begin{array}{l}\left(1^{\text {st }} \text { numerical grid }\right. \\
\text { was used; cf. Figure 1) }\end{array}$ & & & & \\
\hline S2 & $90^{\circ}$ & & $\begin{array}{l}\text { parallel to the little wall of } \\
\text { dihedral configuration }\end{array}$ & 8,3 \\
\hline $\begin{array}{c}\text { S3 } \\
\left(2^{\text {nd }} \text { Numerical Grid }\right. \\
\text { was used; cf. Figure 7) }\end{array}$ & $90^{\circ}$ & & nothing & 0 \\
\hline S4 & $90^{\circ}$ & & $\begin{array}{l}\text { parallel to the the plane bisecting } \\
\text { the dihedral configuration }\end{array}$ & 8,3 \\
\hline S5 & $90^{\circ}$ & & & 16,6 \\
\hline S6 & $135^{\circ}$ & & & 8,3 \\
\hline S7 & $90^{\circ}$ & \multirow{3}{*}{$\begin{array}{c}\text { On the big } \\
\text { wall ofdihedral } \\
\text { configuration }\end{array}$} & nothing & 0 \\
\hline & & & & \\
\hline S8 & $90^{\circ}$ & & $\begin{array}{l}\text { parallel to the the plane bisecting } \\
\text { the dihedral configuration }\end{array}$ & 8,3 \\
\hline
\end{tabular}




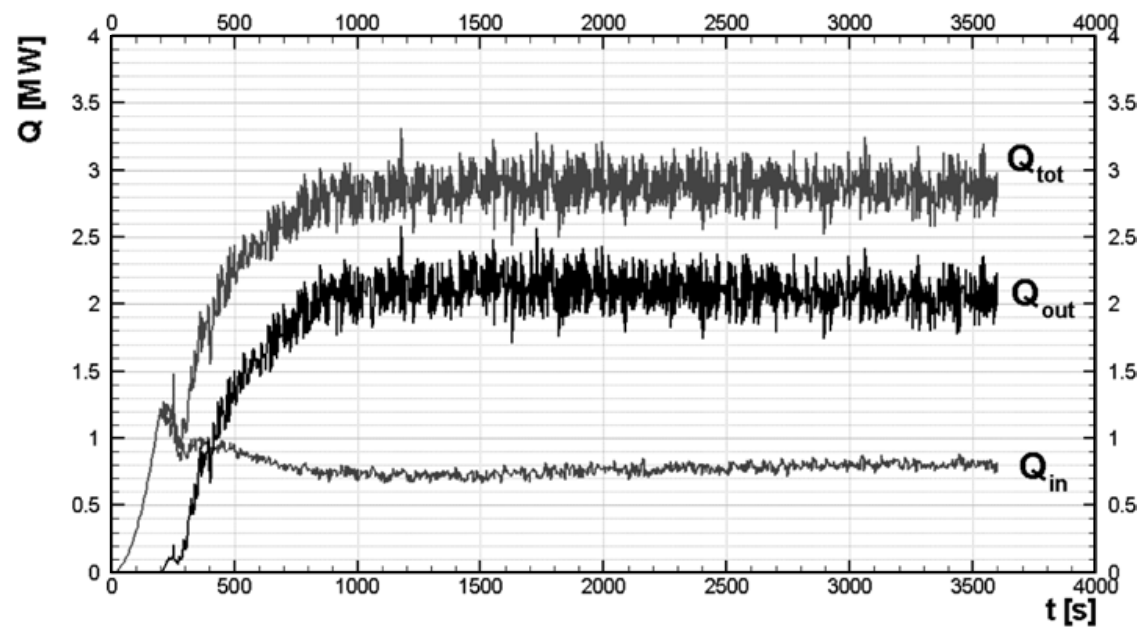

Figure 2. Curve of the power fire development in the time function.

\section{RESULTS AND DISCUSSION}

In this part we detail the work done and give the simulation's features. In order to evaluate the wind influence on the emerging fire plume dynamics, and the comprehension of an eventually stack effect we analyse the output quantities: flow speed field $\left[\mathrm{ms}^{-1}\right]$, temperature flow field $\left[{ }^{\circ} \mathrm{C}\right]$ and the heat rate released by the fireplace $\left[\mathrm{kWm}^{-3}\right]$. All these output variables were recorded each $10 \mathrm{~s}$ of physical time. An average calculus on the total simulation time was performed for each variable, in this way we obtained the average behaviour for each variable.

\section{Simulation S1}

Firstly, in order to control the fire plume parameters, the nominal power fire was measured into the total numerical volume. Figures 2 and 3 show power fire curve development in function of the time.We observed that the total power fire $\boldsymbol{Q}_{\text {tot }}$ is near of $3 \mathrm{MW}$, the fire plume power $\boldsymbol{Q}_{\text {out }}$ (emerging throw the room's window) is near of $2 \mathrm{MW}$, as desired, and the fire into the room $\boldsymbol{Q}_{\boldsymbol{i n}}$ is near of $1 \mathrm{MW}$.

Analyzing the power curve (cf. Figure 2), we identify the main states of the fire development:

the first into the room and the second when the fire plume emerges from the room through the window. In this way we observed the instant when the fire activity goes from the fire regime named "controlled by the rate of pyrolysis fuel gas production", to the fire regime named "controlled by the ventilation". In this second fire regime, the oxygen $\boldsymbol{O}_{2}$ necessary to the combustion process comes from the outdoor and enters through the open window into the room's volume. In ours case the fire phenomena, controlled by the ventilation, arrives at 195 seconds after the fire starting. At this instant (195 s), the amount of oxygen $\boldsymbol{O}_{\mathbf{2}}$ into the volume's room was consumed. The upper area window being blocked by the hot combustion gases coming out, these gases are at pressure bigger than the outdoor pressure. The gases coming out, burn and form the fire plume. At this time the oxygen $\boldsymbol{O}_{2}$ necessary to the combustion process, enters throw the bottom middle area of the open window. The interphase (imaginary line) defining the border between the upper and bottom window's zones is characterized by a gradient of pressure $\mathrm{dp} / \mathrm{dy}=0$. The height of the fire plume in a quiet atmosphere was calculated being about $7,5 \mathrm{~m}$. 


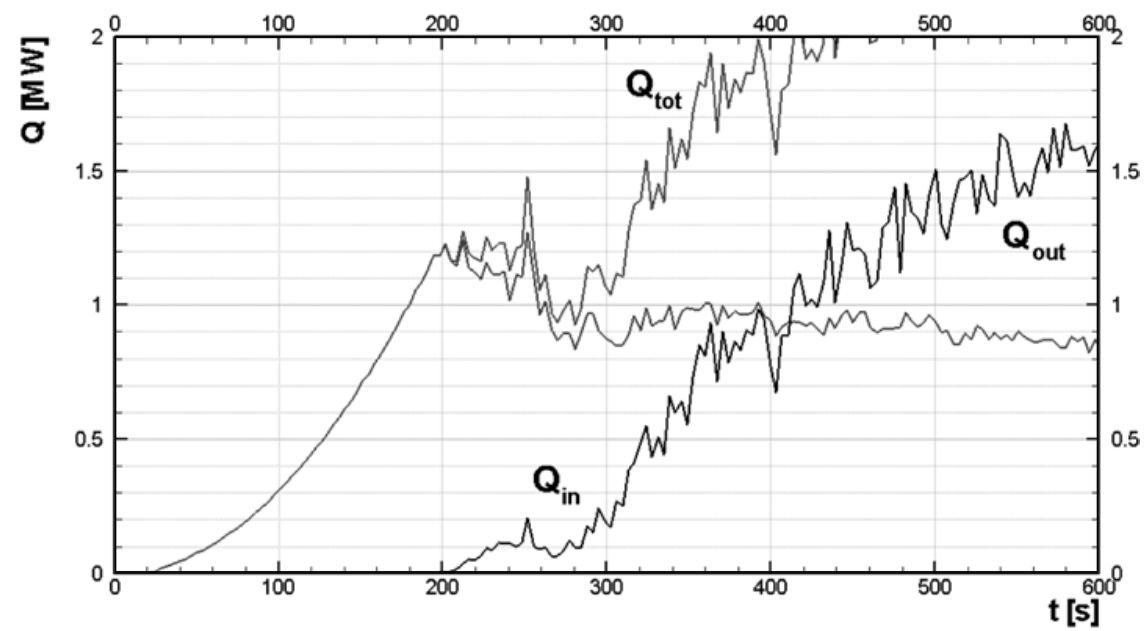

Figure 3. Curve of power fire plume development: time of the fire regimes separation.
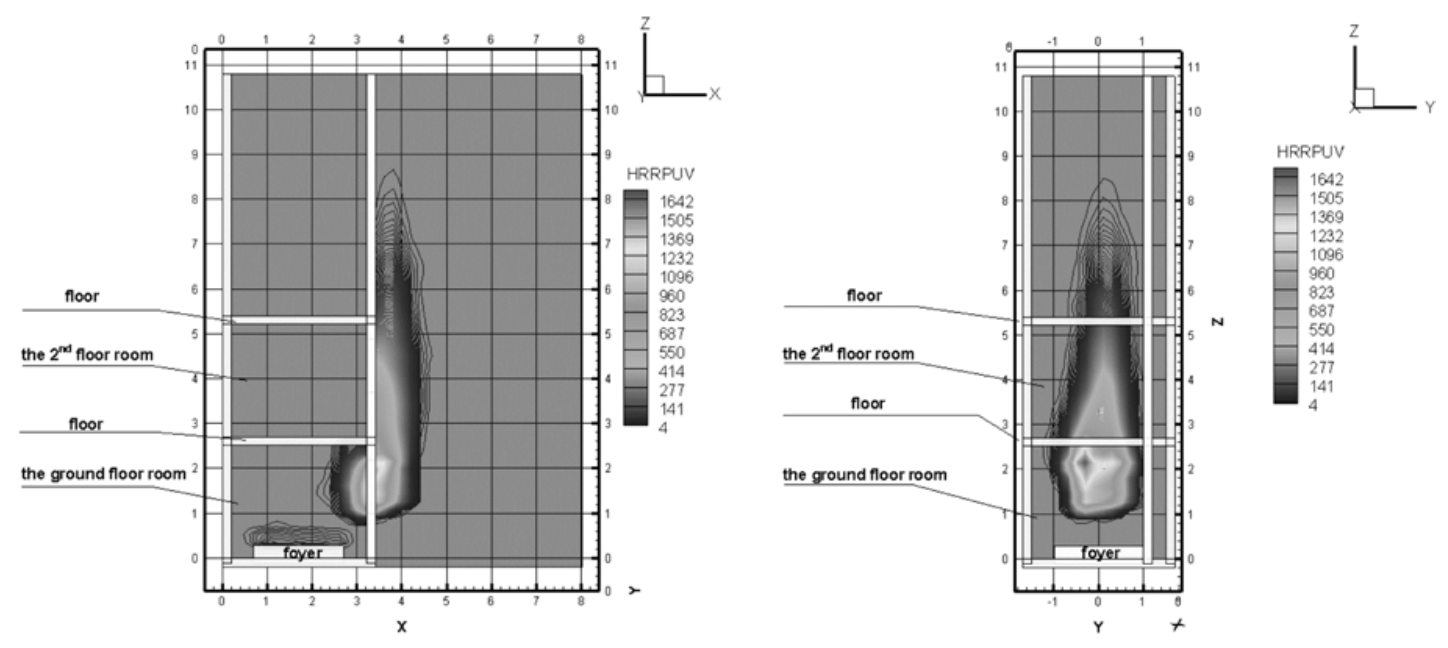

Figure 4. Field of heat release rate per unit of volume $\mathrm{kW}^{-3}$ : plane $\mathrm{XZ}$ in the left and $\mathrm{Y} Z$ in the right.

\section{Simulations S2 and S3}

In S2 (condition of the frontal wind with a wind velocity equals to $8,3 \mathrm{~ms}^{-1}$ ). The results shows (Fig. 6) that the fire plume is pushed and deformed against the big wall under the wind influence. This can be explained by the pressure gradient caused by the wind. In opposite way S3 (wind velocity equals to $0 \mathrm{~ms}^{-1}$ ) shows that the fire plume is symmetrical respect to the central window axis. It is not influenced by the wind.

\section{Simulations S4, S5 and S6}

For S4 (frontal wind with a wind velocity equals to $8,3 \mathrm{~ms}^{-1}$ ), the results (Fig. 9) shows the strong wind influence on the fire plume emerging throw the window. Figure 9 shows on the left figure the temperature field and on the right figure the velocity field. The left figure shows that the average position of the fire 


\section{MATEC Web of Conferences}
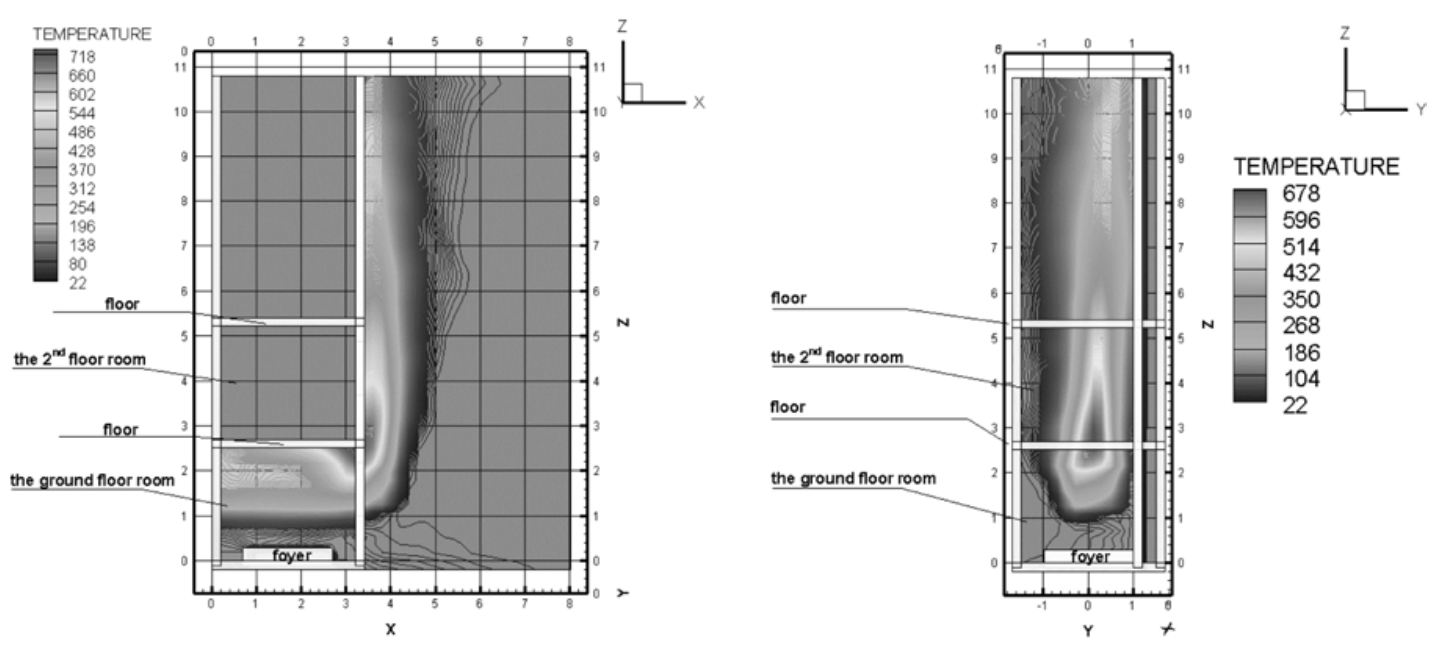

Figure 5. Field of temperature ${ }^{\circ} \mathrm{C}$ : plane $\mathrm{XZ}$ in the left, plane $\mathrm{Y} Z$ in the right.

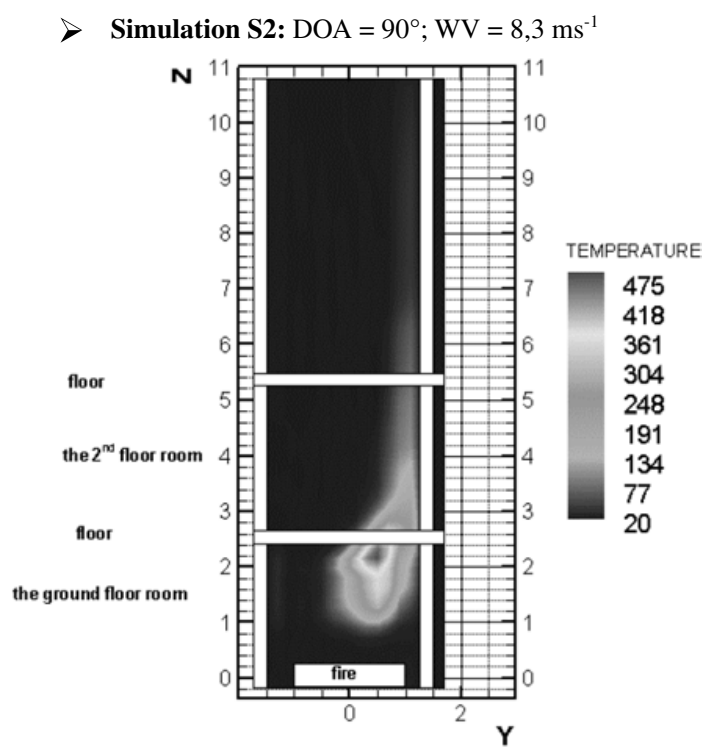

Figure 6. Field of temperature ${ }^{\circ} \mathrm{C}$ : plane $\mathrm{YZ}$.

plume is near from the exterior corner of dihedral configuration (angle of $270^{\circ}$ ). The velocity field shows an acceleration of the plume flame near from the exterior corner of dihedral configuration (angle of $270^{\circ}$ ), also we noticed that he fluid lines are deformed under the walls influence, this have as result, the elevation of static pressure nears from the walls, so is observed that this effect only caused by the wind and not by the stack effect. So the dynamics behaviour of the fire flame is only drive by the pressure gradient caused by the wind. In S5 (frontal wind, wind velocity equals to $16,6 \mathrm{~ms}^{-1}$ ), the wind influence on the fire flume is more important than in S4 case. The fire plume is strongly perturbed and deformed by the wind. The fire plume is pushed against the exterior walls of the dihedral configuration near the corner forming an angle of $270^{\circ}$. This confirms that flame dynamics is only drive by the pressure gradient caused by the wind and not by the supposed stack effect. S6 (frontal wind, wind velocity 
Simulation S3: $: \mathrm{DOA}=90^{\circ} ; \mathrm{WV}=0 \mathrm{~ms}^{-1}$

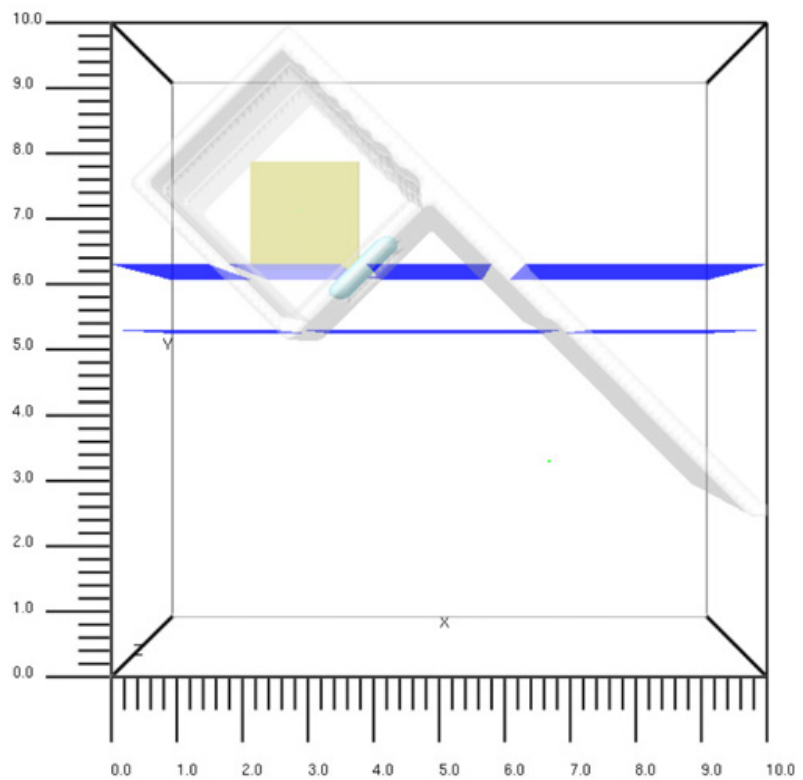

Figure 7. Numerical domain of simulations $\mathrm{S} 3$ to $\mathrm{S} 6$.

temperature field $\left.\mathrm{T}^{\circ} \mathrm{C}\right]$ at $z=3,59 \mathrm{~m}$

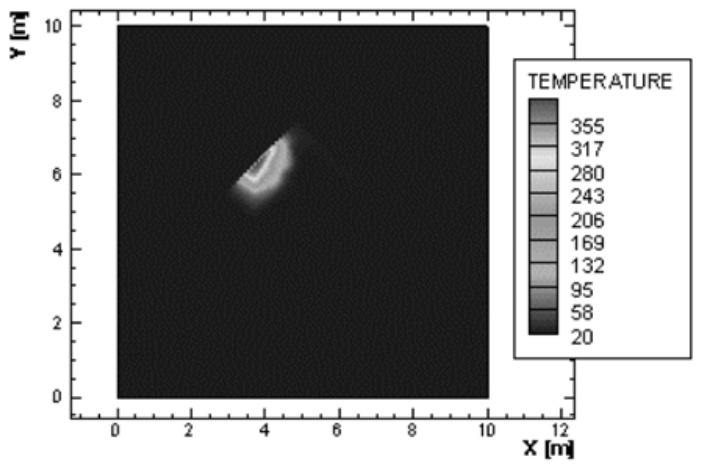

velocity field $\mathrm{v}[\mathrm{m} / \mathrm{s}]$ at $\mathrm{z}=3,59 \mathrm{~m}$

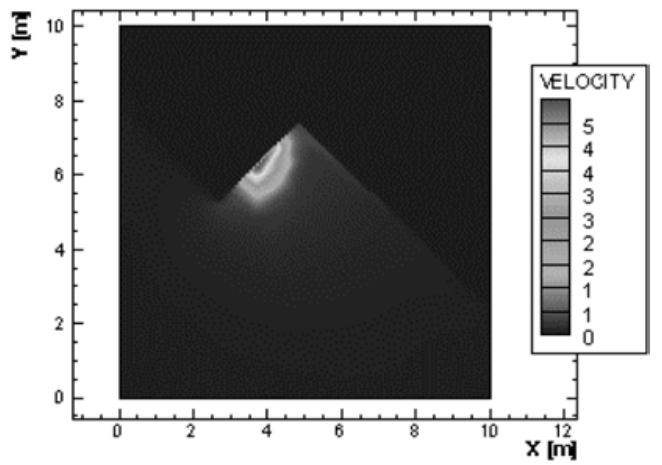

Figure 8. Fields of temperature (left) and velocity (right); fields takes on the plane $X Y$ at $Z=3,59 \mathrm{~m}$ (near the second floor window), from the floor $(Z=0)$.

$8,3 \mathrm{~ms}^{-1}$, opening dihedral angle $135^{\circ}$ ) shows also the wind influence on the fire plume dynamics and confirms again that the fire plume dynamic is only derived by the pressure gradient caused by the wind. The opening dihedral angle of $135^{\circ}$ contributes to lowering the level of the pressure gradient and thereby the value of the escape velocity of the fire plume at each side of the dihedral configuration.

\section{Simulations S7 and S8}

In this simulation we notice also the wind influence on the fire plume behaviour. The different windows position (on the big wall forming the dihedral) does not add significant changes. 
Simulation S4: DOA $=90^{\circ} ; \mathrm{WV}=8,3 \mathrm{~ms}^{-1}$

tem perture field $\mathrm{T}\left[{ }^{\circ} \mathrm{C}\right]$ à $z=3,69 \mathrm{~m}$

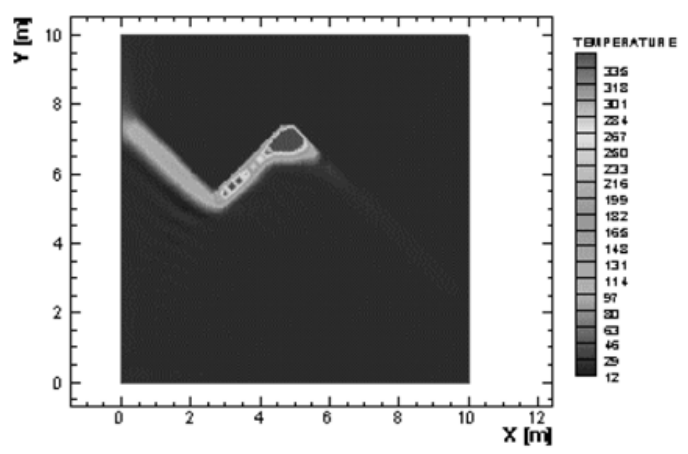

velocity field $\mathrm{v}[\mathrm{m} / \mathrm{s}]$ at $\mathrm{z}=3,69 \mathrm{~m}$

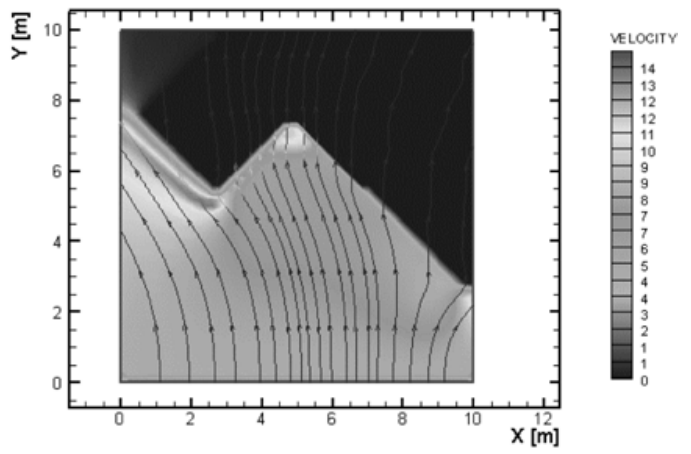

Figure 9. Fields of temperature (left) and velocity (right); fields takes on the plane $X Y$ at $Z=3,69 \mathrm{~m}$ (near the second floor window) from the floor $(Z=0)$.

Simulation S5: DOA $=90^{\circ} ; \mathrm{WV}=16,6 \mathrm{~ms}^{-1}$

temperature field $\left[{ }^{\circ} \mathrm{C}\right]$ at $\mathrm{Z}=3,59$

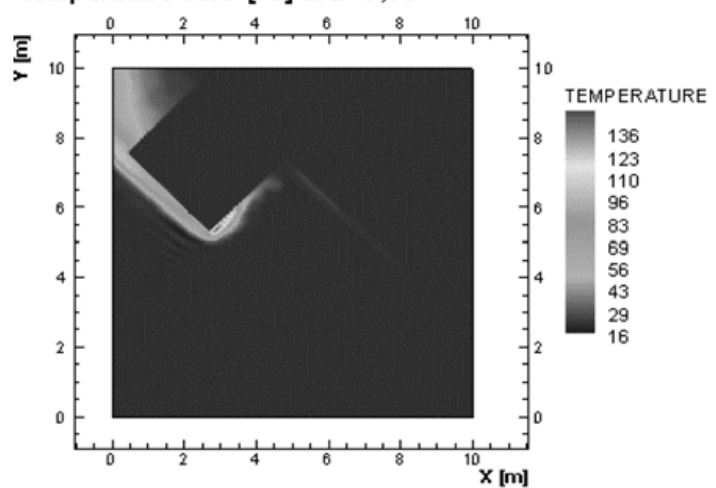

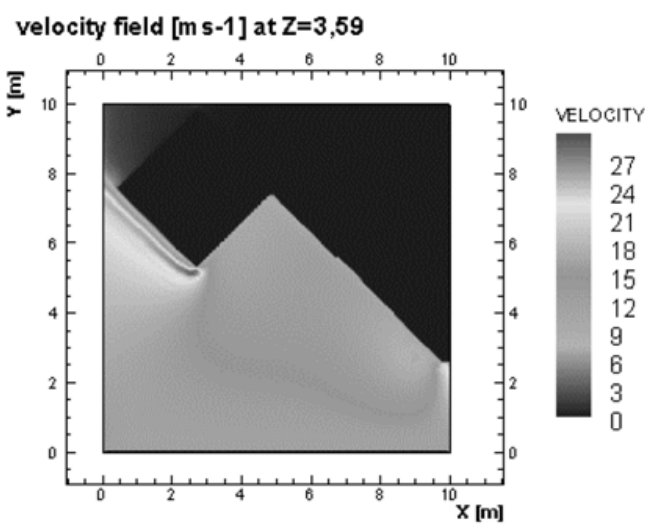

Figure 10. Fields of temperature (left) and velocity (right); fields takes on the plane $\mathrm{XY}$ at $Z=3,59 \mathrm{~m}$ (near the second floor window) from the floor $(Z=0)$.

\section{Summary of the results}

Here DOA means Dihedral Opening Angle and WV means wind velocity):

Simulation $1\left(\mathrm{S1}: \mathbf{D O A}=\mathbf{9 0 ^ { \circ }} ; \boldsymbol{W V}=\mathbf{0} \mathbf{m s}^{-1}\right)$ : In the absence of wind the stack effect is near none existing if the wall forming the angle $90^{\circ}$ is at $0,6 \mathrm{~m}$ from the window in a frontage of façade. In this case the fire plume coming out through the window is almost symmetrical to the vertical axis of the window.

Simulation $2\left(\mathbf{S} 2: \mathbf{D O A}=\mathbf{9 0} ; \boldsymbol{W V}=\mathbf{8 , 3} \mathbf{m s}^{-1}\right)$ : If a wind of $30 \mathrm{~km} \mathrm{~h}^{-1}$ is present and it is parallel to the window plane (parallel to the little wall of dihedral configuration), the fire plume coming out through the window is pushed against the wall forming the angle $90^{\circ}$.

Simulation $3\left(\mathrm{S3}: \mathrm{DOA}=\mathbf{9 0}^{\circ} ; \boldsymbol{W V}=\mathrm{O} \mathrm{ms}^{-1}\right)$ : The conclusion is similar to the conclusion for $\mathrm{S} 1$.

Simulation $4\left(\mathbf{S 4}: \mathbf{D O A}=\mathbf{9 0 ^ { \circ }} ; \mathbf{W V}=\mathbf{8 , 3} \mathbf{m s}^{-1}\right)$ : If a wind of $30 \mathrm{~km} \mathrm{~h}^{-1}$ is present and is parallel to the plane bisecting the dihedral configuration, a little fire plume deformation is observed near the dihedral origin. This "stack effect" is not strong and less important as the dynamics system. The dynamics of fluid of fire plume is driven by the pressure gradient. The fire plume coming out through the window is pushed against the big wall forming the angle $90^{\circ}$ a little more than in S1 and S3. 
Simulation S6: $\mathrm{DOA}=135^{\circ} ; \mathrm{WV}=8,3 \mathrm{~ms}^{-1}$

temperature field $\left[{ }^{\circ} \mathrm{C}\right]$ at $Z=3,69$

velocity field [m s -1$]$ at $Z=3,69$

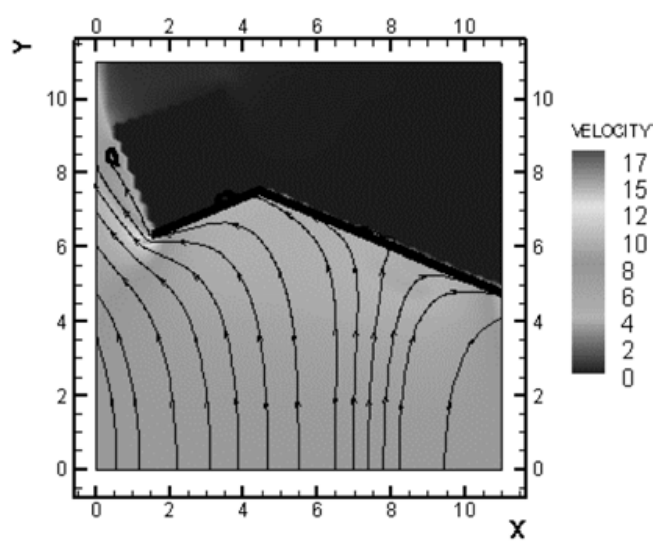

Figure 11. Fields of temperature (left) and velocity (right); fields takes on the plane $X Y$ at $Z=3,69 \mathrm{~m}$ (near the second floor window) from the floor $(Z=0)$.

Simulation S7: DOA $=90^{\circ} ; \mathrm{WV}=0 \mathrm{~ms}^{-1}$

tem perature field $[\mathrm{C}]$ at $\mathrm{Z}=3,59$

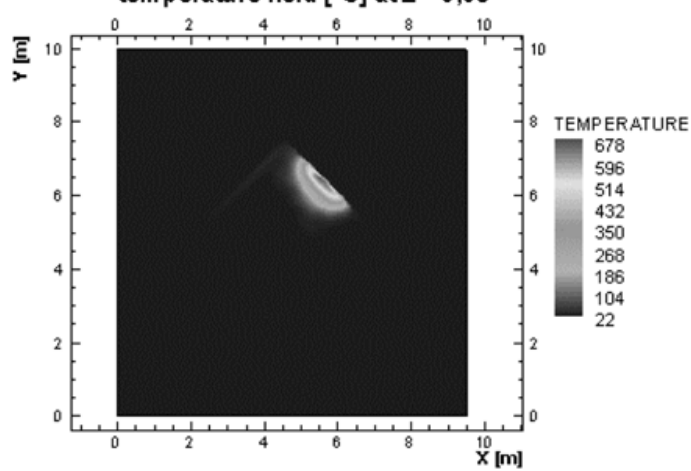

velocity field $\mathrm{m} \mathrm{s-1}$ at $\mathrm{Z}=3,59$

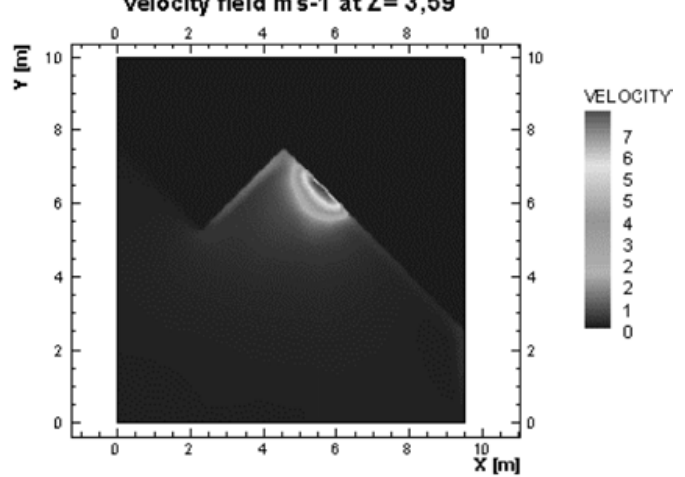

Figure 12. Fields of temperature (left) and velocity (right); fields takes on the plane $\mathrm{XY}$ at $Z=3,59 \mathrm{~m}$ (near the second floor window) from the floor $(Z=0)$.

Simulation $5\left(\right.$ S5: DOA $\left.=90^{\circ} ; \boldsymbol{W V}=16,6 \mathrm{~ms}^{-1}\right): \quad$ If a wind of $60 \mathrm{~km} \mathrm{~h}^{-1}$ is present and is parallel to the the plane bisecting the dihedral configuration, the fire plume coming out through the window is strongly perturbed and pushed towards the exterior of the small wall forming the angle $90^{\circ}$ (absence of stack effect).

Simulation $6\left(S 6: D O A=135^{\circ} ; W V=8,3 \mathrm{~ms}^{-1}\right)$ : With an angle of dihedral of $135^{\circ}$ and a win of $30 \mathrm{~km} \mathrm{~h}^{-1}$, the fire plume coming out through the window is strongly perturbed and pushed towards the exterior of the small wall forming the angle $135^{\circ}$ (absence of stack effect).

Simulation 7 (S7: DOA $\left.=\mathbf{9 0 ^ { \circ }} ; \boldsymbol{W V}=\mathbf{0} \mathbf{m s}^{-\mathbf{1}}\right)$ : Conclusion is similar to S1 and S3 (weak stack effect).

Simulation $8\left(S 8 D O A=90^{\circ} ; W V=8,3 \mathrm{~ms}^{-1}\right)$ : In this case the fire plume coming out through the window is strongly pushed against the big wall forming the angle $90^{\circ}$, it is explained by the deflection of the wind on the solid area of the big wall. 


\section{MATEC Web of Conferences}
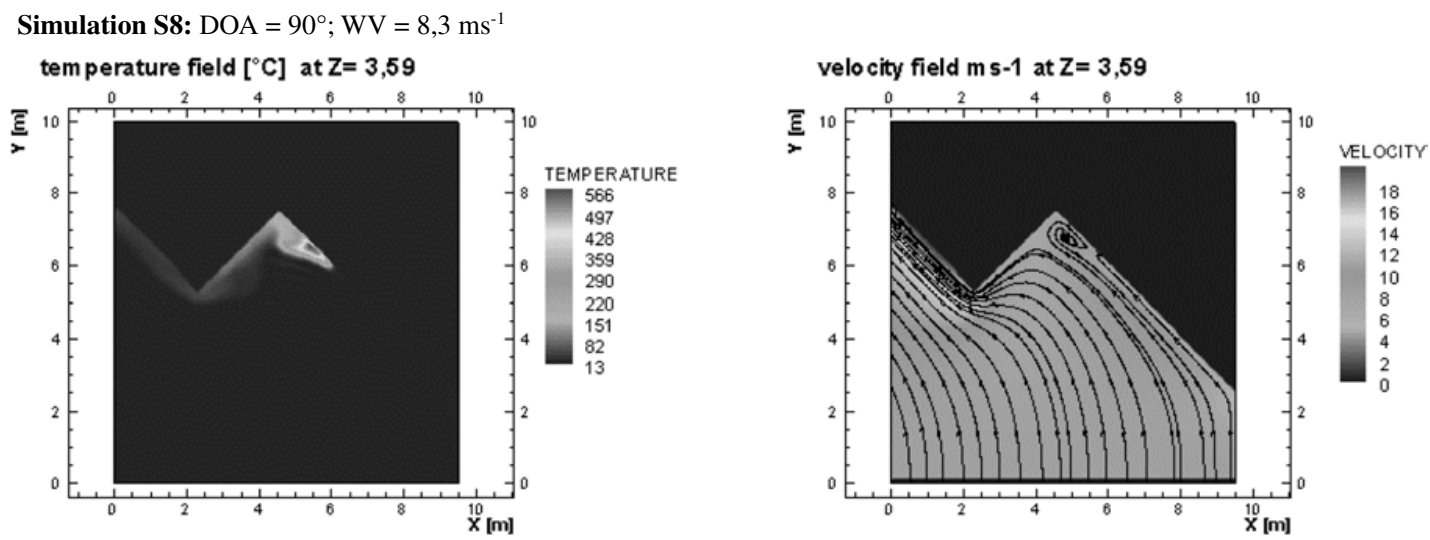

Figure 13. Fields of temperature (left) and velocity (right); fields takes on the plane $X Y$ at $Z=3,59 \mathrm{~m}$ (near the second floor window) from the floor $(Z=0)$.

\section{CONCLUSION}

The work was performed to study whether the dramatic fire that occurred in Dijon (France) in 2010 was influenced by the stack effect. The study showed that this is not the case. The wind influence is preponderant at the supposed stack effect.

In this study we did not take into account the pyrolysis of the walls (formed by the organic reinforced coating and expanded polystyrene) and we did not evaluate his influence on the vertical extension of the fire by the outside. In order to include the pyrolysis phenomena of the walls, the development of the pyrolysis models is a desirable and interesting subject for futures researches.

The study author gratefully acknowledges HOGNON Bernard, chief engineer, in charge of "Regulatory Studies fire" in the direction of security structures and fire at the CSTB for all his assistance in the analysis of results and for the preparation and formulation of the study report.

\section{References}

[1] SFPE, "The SFPE Handbook of Fire Protection Engineering”, SFPE and NFPA Publishing, Quincy Massachusetts, 2008.

[2] Vytenys Babrauskas, "Ignition Handbook", FSP, SFPE, Published by Fire science Publishers, 2003.

[3] K. McGrattan et al. "Fire Dynamics Simulator (version 5) User' Guide". NIST Special Publication 1019-5, April 2010.

[4] K. McGrattan et all. "Fire Dynamics Simulator (version 5) Technical Reference Guide".NIST Special Publication 1019-5, April 2010.

[5] Drysdale, D, "An Introduction to Fire Dynamics", John Wiley \& Sons, 1985.

[6] M. Faghri, B. Sundén. "Transport Phenomena in Fires", WIT press, 2008.

[7] S.B. Pope. "Turbulent Flows", Cambridge University Press, 2000.

[8] T. Poinsot, D. Veynante. "Theoretical and Numerical Combustion". 2ed. Edwards, 2005. 